\title{
Ensino: uma questão política enredada num absurdo científico ${ }^{1}$
}

Resumo A reflexão que segue visa equacionar alguns dos problemas estruturais do ensino básico e secundário em Portugal no início d século XXI. Incidirá em quatro pontos:

I - A ideologia em forma de ciência;
II - A escola e a regulação de relações entre pessoas;

III - O sistema de avaliação como reflexo da escola que temos;

IV - O dilema da função docente: servir o aluno ou servir o conhecimento?

\section{I - A ideologia em forma de ciência}

A escola vive uma grave crise de identidade enquanto espaço social simbólico. Para tentar ultrapassar isso será necessário romper com a ideologia «anti-conhecimento" que domina o sistema escolar, perfeitamente espelhada nas correntes dominantes das auto-denominadas «ciências da educação» e na cultura hedonista que as caracteriza e que ganhou forte expressão social

Este é o mais importante nivel em que se tem de situar o problema da crise cultural, seja cientifica, seja humanista. A essência do problema reside, sem dúvida, nos decisivos ensinos básico e secundário.

Parece-me óbvio que os três pilares em que assenta (e sempre assentou) o sistema de ensino são:

\section{9) o conhecimento; \\ 2. ${ }^{\circ}$ ) professor; \\ 3.') e o aluno.}

Nấo é por acaso que os coloco por esta ordem.

De modo nenhum pretendo desvalorizar qualquer deles, mas tão só mostrar que é um erro não tomar o conhecimento como o «sector de ponta» do sistema de ensino e, como consequência, será também um erro não considerar o professor, antes e acima de tudo, como um transmissor de conhecimentos. Ensino básico quer dizer precisamente isso: transmitir saberes elementares, algo em que se tem sistematicamente falhado. Cumprida essa funçăo, o professor pode ser tudo o resto.

É um erro grave, particularmente no ensino básico, considerar o professor, em primeiro lugar, como um animador de aprendizagens ou de auto-aprendizagens dos alunos. Essa deriva visionária da função docente tem de ser invertida.

A raiz do desastre está precisamente nas paranóicas pedagogias activas centradas no aluno

Parece evidente que o problema do ensino é e sempre foi um problema político, concretamente um problema ideológico. Para se fugir a essa dimensão incómoda, precisamente porque não se tem sabido lidar com ela dada a inabilidade das utopias em lidar com o contraditório, criou-se um mecanismo ilusório para erradicar a dimensão política ou ideológica do ensino que está a ter efeitos gravemente perversos.
Ele deixou o ensino e, portanto, a essência do nosso projecto de sociedade, nas mãos de uma minoria supostamente iluminada.

Essa minoria iluminada agrega-se em torno das ditas ciências da educação. Ao tentarem tornar científico o que é político - ou, na melhor das hipóteses, o que é cultural, do bom senso, do senso comum, da tradição de ensinar, do domínio da opinião, do livre debate de pontos de vista - as ciências da educaçăo acabaram por ter o efeito de radicalizar a dimensăo política, tornando o nosso ensino dogmático e muito colado à conjunturả revooluciơnária dós anoós 70 em que foi moldado?

O grave é que isso está a ser feito de modo inconsciente, numa espécie de "caldo de cultura política monolítica" que vai acumulando sucessivas vitórias contra o conhecimento, precisamente no núcleo duro onde isso jamais deveria acontecer: no sistema de ensino.

O que há de saberes académicos ou científicos no ensino (refiro-me, em particular, ao ensino básico e secundário) são as ápeas disciplinares - o português, a matemática, a história, a geografia, a filósoofiả, à físicà, à químiçả, etć. - e nunca uma visão global sobre o ensino.

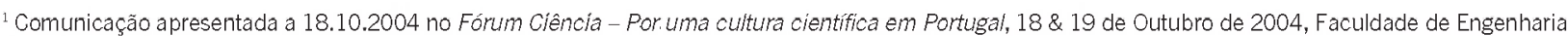
da Universidade do Porto.

* Professor de Histórià do ensino secundário - Almada (mitharibeiro@net.sảpo.pt) 
Currículos, regulação de relações de trabalho no contexto da instituição-escola, cargas horárias, sistemas de avaliação, gestão das escolas, etc., isto é, aquilo que é a essência das ciências da educação, nada tem a ver com o conhecimento científico ou académico necessário e indispensável a professores e alunos. Tem a ver com opções políticas no sentido puro e duro, a debater nos espaços de cidadania e de decisão política das nossas democracias, e não pode estar preso ou dependente de qualquer pretensa ciência. Esse é um dos nossos grandes equívocos: transformou-se, com um golpe de magia, o que era político em pseudo-científico, à custa precisamente da menorização do conhecimento científico.

\section{II - A escola e a regulação de relações entre pessoas}

Muitas vezes quando se discutem os deficientes ou mesmo maus resultados das aprendizagens dos alunos no ensino básico e secundário, que depois se reflectem no ensino superior (mesmo sabendo que aí só chegam as elites), tendemos a omitir um elemento crucial: a indisciplina. Os contextos em que decorrem as aprendizagens (hoje e sempre) são decisivos. Refiro-me, em concreto, aos ambientes de sala de aula. Se aí não houver silêncio ou, no mínimo, tranquilidade, tudo o resto fica negativamente condicionado. A esmagadora maioria dos princípios pedagógicos que nos dominam apontam precisamente no sentido da histeria: da sala de aula e da escola.

Na verdade, só com uma grande dose de ingenuidade ou de cinismo é que nós não consideramos a questão da indisciplina como um dos problemas mais sérios das nossas escolas.

A raiz do problema da indisciplina tem a ver com dois pontos que me parecem cruciais:

$\left.1 . .^{\circ}\right)$ a maneira como se concebe a relação professop/aluno/instituição-escola (dimensão ideológica);

2.') a inexistência, nas escolas, de estratégias objectivas para enfrentar o problema da indisciplina (dimensão administrativa) ${ }^{3}$.
Vou abordar apenas, de forma sucinta, o primeiro aspecto - maneira como se concebe a relação professor/aluno/instituição.

As correntes pedagógicas centradas no aluno criaram a falsa ideia da parceria ou da irmandade entre professores e alunos. Como consequência todos nós (dentro e fora da escola, mas sobretudo entre os docentes do básico e do secundário) passámos a dar relevância à hipótese errada de que tudo deve ser negociado com os alunos. Desde questões científicas, passando pelo cumprimento de programas, pela regulação de comportamentos ou pela avaliação, para se chegar à gestão partilhada dos espaços dentro da escola.

"Na verdade, só com
uma grande dose
de ingenuidade ou de
cinismo é que nós não
consideramos a questão
da indisciplina como um
dos problemas mais sérios
das nossas escolas."

Por muito que a realidade depois negue esse princípio idílico, paira sempre a ideia perversa de que adultos/professores, por um lado, e crianças/adolescentes/alunos, por outro lado, são pares e devem buscar permanentemente pontos de negociação como forma de meIhor prevenir e resolver os problemas, muitas vezes aparecendo até como a única via.

Nada de mais errado ou, no mínimo, duvidoso. É aí que reside a «fonte-mãe» da fraqueza dos professores, da sua forte tendência para a demissão do seu papel de liderança, e por aí se alimenta a indisciplina.

A indisciplina está precisamente nos antípodas da cultura do saber.

Uma instituição específica com as características da escola não pode assen- tar num contrato social onde paire a ideia de que está permanentemente tudo em aberto, para que a todo o momento professores e alunos negoceiem.

Em contexto escolar o contrato social implica (ou tem de implicar), obrigações mútuas de parte a parte, praticamente todas definidas logo à partida. Quanto mais especiffica for uma instituição, menor será a margem de negociação ou entâo é a própria ideia de instituição que perde sentido.

É evidente que isso pressupõe obrigações para os professores. Isso é indiscutivel. E a obrigação dos professores é ensinar. No entanto, ao contrário do que muitos pedagogos tendem a sugerir, é errado pensar que, na actual conjuntura, o problema da indisciplina tenha a sua origem na transmissão de conhecimentos pelos professores em sala de aula. Não está. Está nos ideólogos do sistema que têm impedido que a sala de aula seja um espaço para a tranquilidade do saber.

Se fizermos incidir a nossa visão sobre o ensino, antes e acima de tudo, no conhecimento, muitos dos problemas disciplinares que temos seriam resolvidos ou mais facilmente delimitados e abríamos, de facto, a porta para a cultura científica e para a cultura humanística.

A questão da indisciplina e, no geral, do fracasso da escola está também, sem dúvida, relacionada com outra ideia feita em que muitas vezes todos embarcamos:

"Os encarregados de educação são elementos decisivos no processo educativo dentro da escola» (sublinho intencionalmente a expressão).

Só tenho razões para discordar desse apriorismo que, para mim, é insensato.

A relação entre a escola, a família e a comunidade é um dos assuntos que tem sido tratado de ânimo leve e tem subjacente a ideia de que os professores são incapazes de darem um rumo à instituição-escola: por falta de capacidades, por falta de competência, por falta de interesse, por comodismo ou por razões corporativas. $O$ resultado perverso da tónica excessiva na necessidade demagógica de aprofundar a relação escola, família e comunidade tem-se traduzi- 
do no enfraquecimento do corpo docente, na sua marginalização

A verdade é que são cruciais para o sucesso de qualquer sistema de ensino as consciências dos professores e o que realmente se passa na intimidade da sala de aula onde tudo pode ser pervertido. Tem-se passado sempre ao lado disso, e essa é uma das razões centrais para os sucessivos fracassos das reformas do ensino. Os "negociadores" têm sistematicamente confundido um "lobby" minúsculo, mas poderoso, que associa os representantes dos sindicatos, as correntes dominantes das ciências da educação e alguns políticos demagógicos, têm confundido isso com o corpo heterogéneo e vasto dos professores.

Se algum grupo profissional tem de ser auscultado pela voz própria de cada um, e não por representatividade, é precisamente o dos docentes do ensino básico e secundário, de tal maneira estão distorcidas ou desacreditadas as formas de representatividade hoje existentes, dentro e fora das escolas.

O produto final dessa relação perversa entre a escola, a família e a comunidade tem sido uma perda prejudicial da identidade da escola enquanto espaço específico de conhecimento. Ou seja, estamos face a uma escola que vai perdendo a dimensão institucional que a deveria caracterizar, uma êscolà que tende a deixar de viver virada para dentro (em torno da escrita, da leitura, do cálculo e dos "agentes de dentro"), uma escola que se quer confundir, em tudo, com a comunidade, perdendo aquilo que the é específico.

É preciso colocar a questão da necessidade de isolar algumas dimensões da vida escolar de tudo o resto, como condição sine qua non do sucesso do ensino, particularmente nos domínios que têm a ver côm a avaliaçăo e com a regulação de comportamentos. A tendência cultural hoje dominante é a de utilizar de forma leviana "desculpas sociais" que só servem para desresponsabilizar, muitas vezes de forma inadmissível, atitudes e comportamentos que em nada dignificam a função docente e a escola enquanto instituição
Todos nós sabemos de cor o que é isso do "discurso do coitadinho".

Quer queiramos quer não, a escola é e sempre foi um espaço relativamente artificial no contexto das sociedades em que se insere. É preciso que isso deixe de ser visto como a "causa dos males", como um estigma. Assumir sem complexos essa relativa artificialidade da escola é dar-Ihe dignidade, é dar-Ihe força, é dar-Ihe razão de ser, é reforçar a sua identidade, e é também o melhor caminho para esbater as diferenças sociais no seu contexto.

"Se fizermos incidir a nossa visão sobre o ensino, antes e acima de tudo, no conhecimento, muitos dos problemas disciplinares que temos seriam resolvidos ou mais facilmente delimitados e abríamos, de facto, a porta para a cultura científica e para a cultura humanística."

\section{III - O sistema de avaliação como reflexo da escola que temos}

Um novo modelo de contratualização entre a sociedade e a escola passa também por outro elemento crucial: o sistema de avaliação/classificação do decisivo ensino básico.

O fạcilitismo nâs avaliạcỗes do ensino básico ẻ uma evidência muito mais fảcil de comprovar do que qualquer princípio dás ciênciâs da educação e por ele temos pago e continuaremos a pagar um preço social demasiado elevado.

O actual sistema de avaliaçăo é um espelho fiel da ideologia dominante que, em cerca de duas décadas, conseguiu desvalorizar por completo a aferição minimamente rigorosa dos resultados escolares e, como consequência, descredibilizou socialmente o sistema escolar
Não é por acaso que isso é feito. Sem um sistema de avaliação credível mesmo as mais aberrantes pedagogias e opções curriculares vão-se auto-promovendo como modelos de sucesso.

São, sem dúvida, vários os aspectos envolvidos nesta questão. Mas parece-me que a forma de olhar para o problema com objectividade é analisar o sistema de classificação baseado nos níveis de 1 a 5 em vigor no ensino básico. 0 facilitismo vem logo à cabeça: não se admite o zero (0). Esse sintoma, não sendo a essência do problema, encerra em si uma significativa carga simbólica.

O sistema de classificação/avaliação em causa, é preciso que se recorde, nem sempre existiu. Foi introduzido na conjuntura dos anos 70 , num contínuo que destruiu paulatinamente o sistema nacional de exames no ensino básico.

Se a opção pelos niveis de 1 a 5 parecia aceitável aos olhos da época, três décadas depois, perante os efeitos desastrosos que produz a médio e a longo prazo, que desmentem todas as boas intenções que pudessem ter justificado a sua adopção, não equacionar nos dias de hoje a sua substituição é querer manter a decadência e o descrédito do ensino.

Não podemos perpetuar a fuga em frente. O sistema de classificação em vigor permite todo o tipo de manipulações dentro e fora da escola e falseia grosseiramente os resultados escolares dos alunos, inflacionando-os. Constitui a formula perfeita para o sucesso oco de conhecimentos.

E, por isso, necessário rever dois aspectos em simultâneo (um sem o outro pouco adiantarà):

1. $\left.{ }^{\circ}\right)$ alterar o sistema de avaliação/classificação do ensino básico: porquê os níveis de 1 a 5 e porque não a escala de 0 a 20 valores ou outra mais fiável? Todos sabem a facilidade com que se alteram, em poucos minutos numa reunião de avaliaçăo, o nível 2 da reprovação para o nível 3 do sucesso, sem que nada de sólido o justifique, algo que pode acontecer (e seguramente acontece!) numa mesma reuniẫo para alunos que aí chegam com quatro, cinco, 
seis, sete negativas e transitam de ano. Estas manipulações dos resultados escolares são demasiado grosseiras, deveriam mexer com a consciência social e envergonhar-nos a todos. Além do mais, este sistema de classificação de 1 a 5 permite que muitos alunos com positiva no primeiro e segundo períodos estejam praticamente transitados desde essa altura, isto é, três meses antes do final do ano lectivo;

$\left.2 .^{\circ}\right)$ reintroduzir exames nacionais em final de ciclo $\left(1 .^{\circ}, 2 .^{\circ}\right.$ e $3 .^{\circ}$ ciclos) e a todas as disciplinas a partir do $2 .^{\circ}$ ciclo. Fazer incidir exigências apenas em algumas delas (como o português e a matemática) é tentar partir a escola entre o rigor e o carnaval e ir por aí, no meu ponto de vista, só revela tibieza e incapacidade política. Menosprezado durante duas décadas por ideólogos escudados em pseudo-teorias científicas sobre a avaliação, o mecanismo dos exames é um instrumento crucial para qualquer sistema de ensino. Não só porque os exames nacionais pressionariam no sentido do cumprimento de programas, permitiriam que se corrigissem desvios desde o primeiro ciclo do básico, fariam dos terceiros períodos lectivos um esforço de fina de ano e não um carnaval retardado ou verão antecipado como agora acontece, como também porque só será possível distinguir os bons dos maus professores distinguindo os bons dos maus alunos.

É evidente que alterar o sistema de avaliação do ensino básico é uma questão social sensível. Todavia, relacionar mais rigor na avaliação e, por inerência, exigir mais rigor a todo o sistema de ensino, relacionar isso com um hipotético acréscimo de exclusão social só revela espíritos incapazes de confessarem abertamente que consideram os alunos, particularmente os oriundos de meios sociais desfavorecidos, como seres intelectualmente diminuídos a quem pouco ou nada se pode exigir e tudo se deve facilitar. A minha experiência docente com alunos provenientes de segmentos sociais desfavorecidos tem provado precisamente o contrário.
Muitos não querem entender, ou não entendem mesmo, em que medida a escola que hoje temos é ela propria geradora de desigualdade e de exclusão sociais, precisamente por năo ser exigente. Quando rotulo o nosso sistema de ensino de anti-democrático, imoral e socialmente injusto é por estas razões

Isto mostra até que ponto o estado se tem demitido da sua função essencial: facultar aos mais desfavorecidos aquilo que de outro modo jamais terão acesso e que é decisivo para a sua realização pessoal, para a sua valorização social e para o nosso projecto de sociedade.

\section{"Muitos não querem} entender, ou não entendem mesmo, em que medida a escola que hoje temos é ela própria geradora de desigualdade e de exclusão sociais, precisamente por não ser exigente."

\section{IV - O dilema da função docente: servir o aluno ou servir o conhecimento?}

Gostaria neste ponto de referir aqueles que me parecem ser os aspectos centrais da formação dos professores, um outro ponto crucial da crise da cultura científica e da crise da cultura humanista.

$\mathrm{Na}$ formação de professores o problema coloca-se a dois níveis:

1. $\left.{ }^{\circ}\right)$ no domínio das filosofias de ensino que inquinam os professores no inicio e ao longo da carreira;

2. $\left.{ }^{\circ}\right)$ tem a ver com questões orgânicas relacionadas com o funcionamento dos núcleos de estágio e como peso excessivo da classificação da componente pedagógica e didáctica em relação à componente científica ou académica na vida profissional dos futuros docentes.
Limito-me ao primeiro aspecto: as filosofias de ensino que nos dominam. A formação de professores é demasiado séria para ficar nas mãos de pedagogos profissionais e de cientistas da educação, quer no início, quer ao longo da carreira.

E este é um dos importantes desafios em que se têm de envolver os ramos científicos, humanistas ou artísticos do ensino superior.

Dominam uma série de pressupostos que só servem para desvalorizar o papel intelectual dos professores, minando-Ihes a auto-confiança desde que entram na carreira.

Em vez de ser explicado aos professores (presentes e futuros) que a trave mestra da sua função é servir o conhecimento, ensinam-Ihes que estão ali para servirem os alunos. Assim, não pode haver "cultura científica».

Não é por acaso que os Gregos fundaram a escola em torno da philos+sophia (amor ao saber). Os nossos teóricos, julgando ter descoberto a pólvora, subverteram esse princípio de forma no mínimo irracional: ficaram com a philos (com o amor) e no lugar da sophía (da sabedoria) colocaram o aluno. Os resultados estão à vista.

Portanto, logo à cabeça, a lavagem cerebral aos docentes é feita. Sobra um ideal de professor tipo polícia de trânsito entre o aluno e o conhecimento. $O$ activó é o aluno. Por issó, de acordo com ós nossos teóricos, essa actividade intelectual do aluno será potenciada quanto mais apagado for o papel do professor e quanto mais "adaptável" for o conhecimento às características e interesses do sujeito que conhece.

Aqui está um produto mor das ditas "pedagogias activas».

Surgem, depois, na formação de professores, uma catadupa de dogmas contendo, eles próprios, as soluções:

(i) as aulas expositivas são erradas, espelho do egocentrismo dos docentes e da "cultura do autoclismo";

(ii) a negociação em sala de aula de resultados de experiências laboratoriais precárias conduzirá às mais so- 
fisticas leis científicas, quase dispensando ou, pelo menos, simplificando em excesso a maçuda teoria

(iii) tudo o que é abstracto e universal não responde aos anseios do «bom selvagem" que busca soluções concretas para os seus problemas imediatos;

(iv) estudar o passado é coisa de conservadores, sendo decisivo debater o presente;

(v) o conhecimento que supostamente não agrada aos alunos não interessa;

(vi) cumprir programas não é importante, pois o importante é que os alunos se sintam integrados;

(vii) o trabalho de grupo é o supra-sumo das pedagogias,

(viii) os projectos, os brainstormings e os debates em sala de aula são indispensáveis e, por isso, devem ser sistemáticos;

(ix) as avaliações formais escritas são demasiado estereotipadas, dado que não respondem às apetências inatas de cada aluno;

(x) o que é desejável é diversificar as avaliaçốes, valorizando a oralidade e a participação nas aulas, independentemente do tipo de disciplina, dos conteúdos a leccionar ou das condições concretas de trabalho em sala de aula;

(xi) as actividades extra-aula são decisivas, mesmo no âmbito das tradicionais disciplinas de estudo (língua portuguesa, matemática, história, fisica, química, geografia, etc.), ainda que essas actividades sejam correr, saltar, gritar,

(xii) o ruído e a agitação das crianças e dos adolescentes são o seu estado natural;

(xiii) etc., etc., etc

É com base nestes pressupostós que se entra na profissão de professor.

Não sei qual é a base científica de tudo isto.

O que eu sei é que este tipo de discurso tem sido despejado de forma doentia para as cabeças dos professores e para cima do sistema de ensino, sem que nada de sólido o justifique e sem que tenha apresentado, em cerca de duas décadas, outro resultado que não seja a degradação do sistema de ensino e a tendência para o aniquilamento do prestígio dos professores, da sala de aula e da escola.

Na verdade, o «lobby» das ciências da educação tem sido demasiado poderoso. Conseguiu, com sucesso, afastar os professores desde o início e ao longo da carreira das áreas científicas ou académicas em que se formaram, empurrando-os

\section{"Tem existido um insustentável divórcio entre o ensino superior e os ensinos básico e secundário."}

para as áreas pedagógicas e didácticas. Isso é, no mínimo, irracional, inconsciente, danoso. Tal só aconteceu por demissão do poder político democrático e por demissão dos ramos cientificos ou académicos das universidades face aos mágicos cientistas da educação

Tem existido um insustentável divórcio entre o ensino superior e os ensinos básico e secundário. Foi esse divórcio que abriu espaço às ciências da educação. Elas são uma espécie de cancro que se intrometeu entre a investigação e a produçăo científica ou intelectual das universidades, por um lado, e, por outro lado, a necessidade de isso chegar aos alunos do ensino básico e secundảrio pela mâo dos professores que trabaIham nesses níveis. Este, se quisermos, seria o mais importante veículo de "cultura cientifica» (para professores e para alunos).

Julgo ser perda de tempo saber quem virou as costas a quem, mas a verdade é que não podemos ter, por um lado, professores que fazem uma carreira de mais de três décadas sem serem obrigados a ler, estudar, investir na área científica ou académica em que se formaram, por outro lado, universidades que formam cientistas ou académicos que numa parte (mais significativa nuns casos e menos noutros), vão para o ensino básico e secundário e, depois, não querem saber mais deles. A maioria dos ramos científicos ou académicos das universidades (aqui não considero as pseudo "ciências da educação» e ramos afins) não se tem preocupado em organizar permanentes cursos de actualização nas mais diversas áreas, nem tem pressionado o poder político para que esses cursos sejam obrigatórios e creditados, com efeitos pragmáticos na progressão da carreira dos docentes do ensino básico e do secundário

Depois, as próprias universidaces queixam-se candidamente de que os alunos chegam cada vez mais mal preparados ao ensino superior.

Onde está a culpa e a razão no meio de tudo isto?

Porto, 18 de Outubro de 2004

\section{Notas}

2 Para além do que se refere n'A pedagogia da avestruz (Gradiva, 2003), duas breves reflexões sobre a relaçăo entre a ideologia e as correntes pedagogicas dominantes encontram-se nos artigos \&Manifesto anti-sistema» do Público de 16.10.2003 e «O primado da pedagogice» do JLEducacãa de 21.01.2004

${ }^{3}$ A Lei 30/2002 sobre o Estatuto do aluno do ensino năo superiơ do ministério do Prof David Justino visava este dominio administrativo. Mas os efeitos prazgináticos săo menores, por um lado, porque não enfrentou o fundamental domínio ideológico do «ensino centrado no aluno», por outro lado, porque o seu carácter genérico pode deixar quase tudó há mesmá. É o exemplo de unáa mèdidà refơrmistá que podêria sêr útil, mảs que se perde pela sua falta de precisão, por não estar enquadrada numa política global e por aparecer a «conta-gotas». 